\title{
Do We Need to Recognize Intracranial Aneurysms into Aneurysmsome and Aneurysmatic Complex: Need for New Concepts in Pathobiology of Intracranial Aneurysms
}

Received: July 31, 2016; Accepted: August 01, 2016; Published: August 08, 2016

Intracranial aneurysms are balloon-shaped widening of the wall of an intracranial artery, resulting from weakening of the arterial wall. Aneurysms can involve any of the blood vessels in the in the body. Cerebral arteries are most commonly involved and these lesions are called cerebral aneurysms or cerebral aneurysms. Intracranial aneurysms are considered the main surgically correctable cerebrovascular abnormality and are a major cause of subarachnoid hemorrhage (SAH) in adult population. This condition has been described with a prevalence of $0.2 \%$ to $9.9 \%$ in the general population, with an annual incidence of 1-2\% [1].

Many aneurysms continue to increase in size and are at risk of rupture and because their intracranial location, intracranial aneurysms are a potentially life threatening condition. Aneurysmal rupture leads to the cerebrovascular events those can result in mortality and lifelong morbidity [2, 3].

A ruptured brain aneurysm can cause severe and significant medical complications, depending on the specific location of the aneurysm. Subarachnoid hemorrhage causes morbidity and mortality due to the presence of blood (as space-occupying lesion) and local irritation of blood vessels that often leads to vasospasm and ischemic cerebrovascular event to. Between $40 \%$ and $67 \%$ of aneurysms that rupture result in death within the first month, and 10 to $20 \%$ of survivors have higher morbidity. In a sub-group of patients even if an aneurysm does not grow but continue to grow in size it can act a intracranial space occupying lesion resulting in significant morbidity including blurred vision, double vision, numbness or paralysis of the face and other neurological symptoms (depending on the location of aneurysm) [4]. In addition it can also form a thrombus within the aneurysm, leading to embolization into distal arteries, causing ischemic event. Taking into consideration the fact that the aneurysms can have predilection for an early rupture or continue to grow for a considerable size and thus behave like a mass we propose these lesions to categorize into aneurysmsome and aneurysmal complex.
Luis Rafael Moscote-Salazarr, Amit Agrawal2, Marco Zenteno ${ }^{3}$ and Angel Lee ${ }^{4}$

1 Latin American Trauma \& Intensive Neuro-Care Organization, Bogota, Colombia

2 MM Institute of Medical Sciences \& Research, Maharishi Markandeshwar University, Haryana, India

3 Instituto Nacional de Neurologia y Neurocirugia, "Manuel Velasco Suarez" Ciudad de Mexico, Mexico

4 Hospital Angeles Inn Universidad, Chairman teaching department, Ciudad de Mexico, Mexico

Corresponding author: Luis Rafael Moscote-Salazar

- mineurocirujano@aol.com

Neurosurgeon-Critical Care, Red Latino, Latin American Trauma \& Intensive Neuro-Care Organization, Bogota, Colombia.

Citation: Moscote-Salazar LR, Agrawal A, Zenteno $\mathrm{M}$, et al. Do We Need to Recognize Intracranial Aneurysms into Aneurysmsome and Aneurysmatic Complex: Need for New Concepts in Pathobiology of Intracranial Aneurysms. Neurosurg. 2016, 1:3.

\section{Aneurysmsome}

Represents the aneurysmal sac from the neck of it to the dome. Aspects such as the neck, dome, height, maximum diameter and dome/neck ratio are critical in the context of this first structure. This anomaly corresponds to a manifestation of aneurysmal disease.

\section{Aneurysmal Complex}

Represents the aneurysmosome and artery pattern origin of the injury pattern. The definition of these two new concepts is critical to understanding the treatment of aneurysmal lesions and improves the approach and therapeutics. 


\section{References}

1 Bederson JB, Awad IA, Webers DO (2000) Recommendations for the management of patients with unruptured intracranial aneurysms. Circulation 102: 2300-2308

2 Vlak MH, Algra A, Brandenburg R, Rinkel GJ (2011) Prevalence of unruptured intracranial aneurysms, with emphasis on sex, age, comorbidity, country, and time period: a systematic review and meta-analysis. Lancet Neurol 10: 626-636

3 Wermer MJ, van der Schaaf IC, Algra A, Rinkel GJ (2007) Risk of rupture of unruptured intracranial aneurysms in relation to patient and aneurysm characteristics: A updated meta-analysis. Stroke 38: 1404-1410.

4 Weir B (2002) Unruptured intracranial aneurysms: a review. J Neurosurg 96: 3-42. 